\title{
Angiografía Rotacional y Road Mapping como ayuda para intervenciones percutáneas complejas. El caso de una Coartación Aórtica
}

Gonzalo Martínez, Francisco Vergara, Alejandro Martínez.

Centro de Terapia Endovascular.

Hospital Clínico Pontificia Universidad Católica de Chile.

El tratamiento percutáneo de la Coartación Aórtica involucra el cruce del segmento estenótico con una guía y la implantación de un stent expandible con balón, con el objetivo de lograr una dilatación permanente a ese nivel $^{1}$. En la selección y ubicación del stent en el sitio de la coartación se requiere de una correcta visualización de la anatomía vascular para corregir el defecto sin distorsionar estructuras cercanas. Con este fin se utiliza la angiografía con contraste. Sin embargo, esta técnica es limitada porque, normalmente, la precisión anatómica requiere de múltiples proyecciones y elevadas dosis de medio de contraste, sobretodo por el alto flujo sanguíneo a ese nivel. Con el desarrollo de nuevos equipos de angiografía es posible realizar adquisiciones volumétricas al rotar el equipo en un semi-círculo sobre el paciente, al mismo tiempo que se inyecta contraste. Esto permite la reconstrucción de una imagen en 3D del segmento intervenido y la aplicación de un modelo angiográfico superpuesto a la radioscopía convencional, conocido como "road-mapping", que puede facilitar la intervención y disminuir el uso de radioscopía y contraste ${ }^{2}$. A continuación se muestran las imágenes de esta técnica utilizada en la reparación de una Coartación Aórtica. 

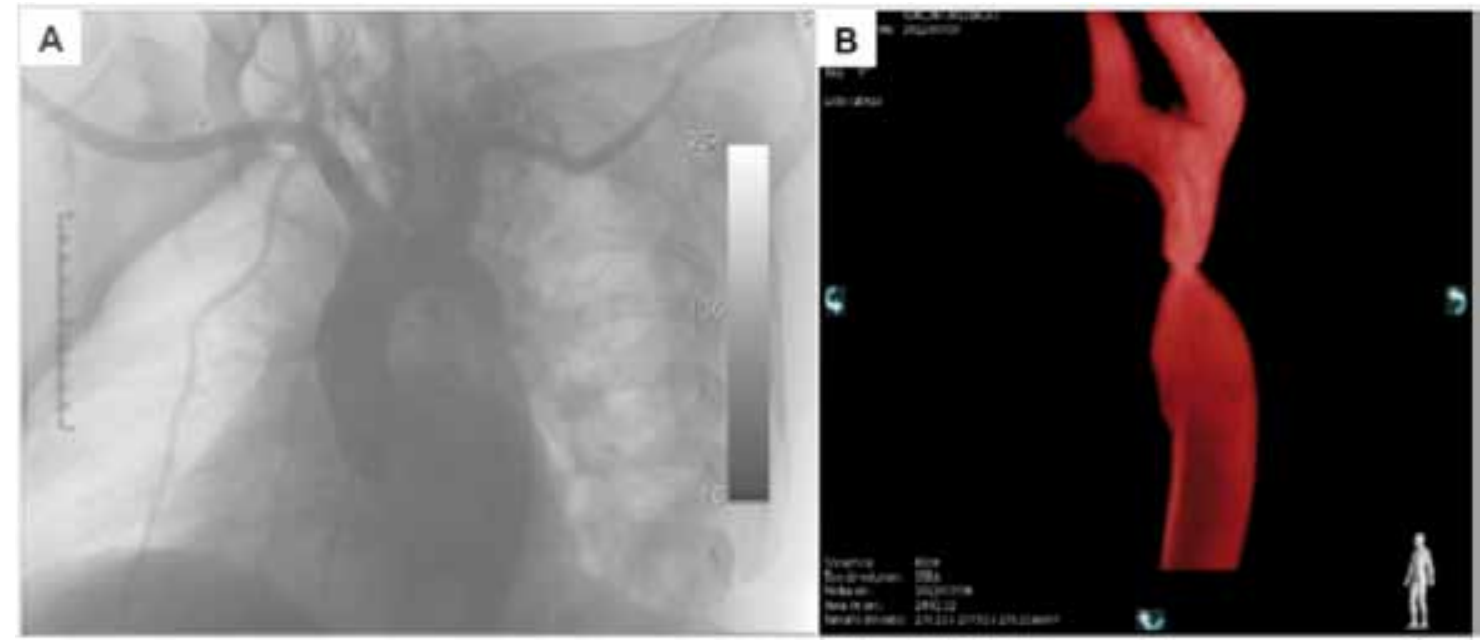

A. Angiografía convencional con contraste que evidencia el segmento coartado en aorta descendente.

B. Reconstrucción tridimensional de la coartación aórtica, con lo cual se consigue una mejor definición del defecto y de su relación con otras estructuras (en este caso, origen de arteria subclavia izquierda). Dado que la imagen 3D puede rotarse, esto permite evaluar con una sola adquisición el defecto en toda su circunferencia.

A

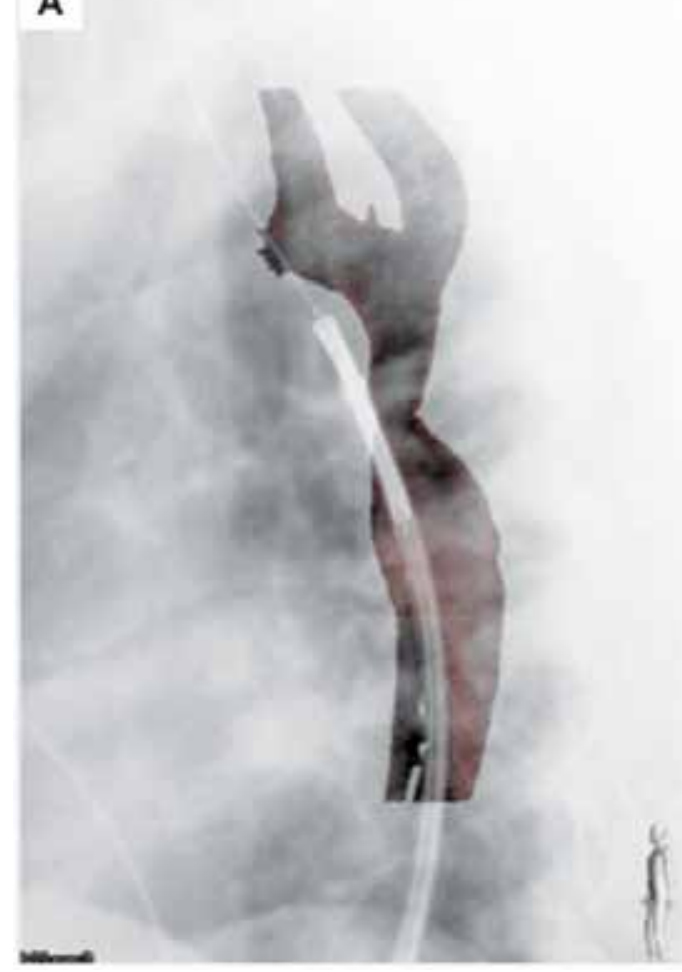

B

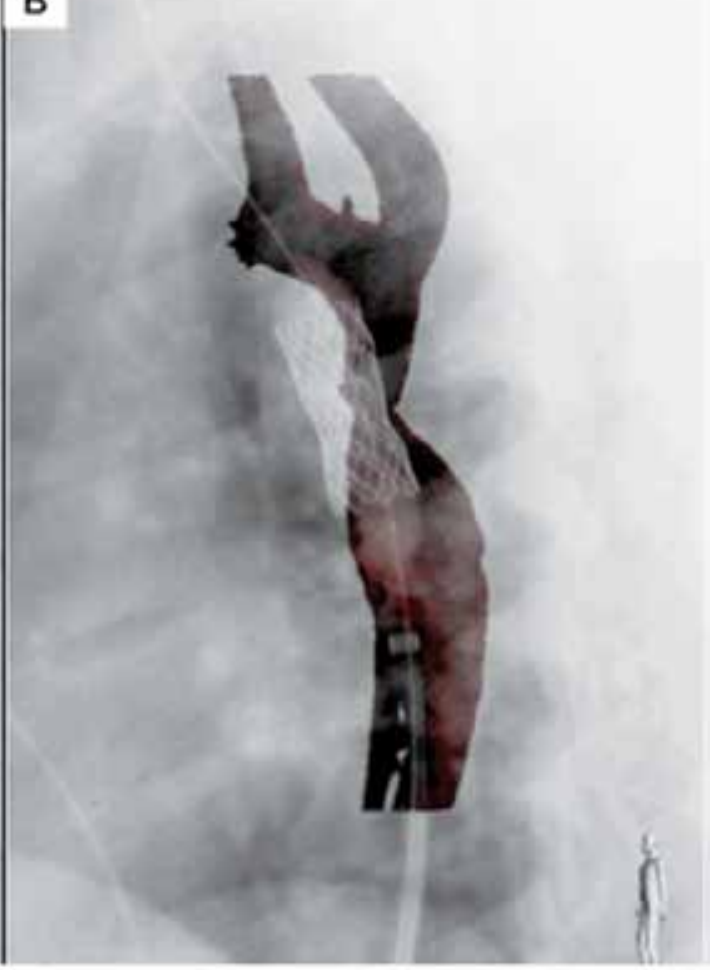

Figura 2.

La reconstrucción tri-dimensional se superpone a la imagen radioscópica en vivo, generando una imagen compuesta que sirve de guía para el cruce del defecto (A) y posteriormente para el implante de un stent (B). Al evitar la adquisición de múltiples cineangiografías, esto permite optimizar el uso de radioscopía y contraste. 
Angiografía Rotacional y Road Mapping como ayuda para intervenciones percutáneas complejas. El caso de una Coartación Aórtica Martínez G., et al.

\section{Referencias.}

1. CHEATHAM JP. Stenting coarctation of the aorta. Catheter Cardiovasc Interv 2001;54:112-125.

\section{FAGAN T, KAY J, CARROLL J, NEUBAUER A. 3-D guidan-} ce of complex pulmonary artery stent placement using reconstructed rotational angiography with live overlay. Catheter Cardiovasc Interv. 2012;79:414-421. 